\title{
A Cellular Automata Model for Simulating Pyroclastic Flows and First Application to 1991 Pinatubo Eruption
}

\author{
Gino M. Crisci ${ }^{1}$, Salvatore Di Gregorio ${ }^{2}$, Rocco Rongo ${ }^{1}$, and William Spataro ${ }^{2}$ \\ ${ }^{1}$ Univ. of Calabria, Dept. of Earth Sciences \& Center of High-Performance Computing, \\ Arcavacata, 87036 Rende (CS), Italy \\ \{crisci, rongo\}@unical.it \\ ${ }^{2}$ Univ. of Calabria, Dept. of Mathematics \& Center of High-Performance Computing, \\ Arcavacata, 87036 Rende (CS), Italy \\ \{toti.dig, spataro\}@unical.it
}

\begin{abstract}
PYR, a first Cellular Automata model for pyroclastic flows, generated by collapsing volcanic columns, is reported in this paper. It was applied to the 1991 Pinatubo eruption (Philippines islands). The model is very simple, but it is able to capture the three-dimensional evolution of the phenomenon in so far as it spreads. Results of the simulations are enough satisfying, if the comparison between real and simulated event is performed, considering the area involved by the event and the thickness of the deposit.
\end{abstract}

\section{Introduction}

Pyroclastic flows are fluidized masses of rock fragments and gases that move rapidly in response to gravity. They can form following the collapse of an eruption column. The flow contains water and gas from the eruption, water vapor and air can be enclosed as it moves downslope; pyroclastic flows can move at rates of $200 \mathrm{~m} / \mathrm{s}$ [3].

At Mount Pinatubo in the Philipines, pyroclastic flow deposits were $220 \mathrm{~m}$ thick in some valleys but averaged 30 to $50 \mathrm{~m}$ thick in others [6], [14]. Pyroclastic flows represent a greatest volcanic hazard; they can incinerate, burn, and asphyxiate people. More people have died due to these hazards than any other volcanic hazard [4].

Differential equations, ruling complex non-linear systems as pyroclastic flows, are very complex and need numerical methods for approximate solutions of real cases. Computer simulation of pyroclastic flows is thus an important goal in order to minimise the hazard, associated to the phenomenon. Cellular Automata $(C A)$ and derived models [8], [12] are widely utilised for simulating complex fluid dynamical systems, whose evolution depends on the local interactions of their constituent parts.

Our research group developed PYR, a first minimal two-dimensional $C A$ model for simulating pyroclastic flows, generated by collapsing volcanic columns. $C A$ computational methods for modelling macroscopic phenomena (adopted successfully in the past to lava and debris flows [8]) are here revised and extended to pyroclastic flows. 
PYR has been tested on a real case event, namely the 1991 Mt. Pinatubo eruption that occurred in the Philippines. The first simulations are encouraging, regarding the extension of the covered area and deposition distribution. They represent a basis to expand this elementary model in order to improve the description of complex geological characteristics of such flows as degassing, deposition and granulometry.

The next section outlines the model, the $C A$ transition function is described in the third section, the Pinatubo eruption features are illustrated in the fourth section, the simulation results are reported in the fifth section, at the end some conclusions.

\section{The $C A$ Model for the Simulation of Pyroclastic Flows}

$C A$ are based on a regular division of the space in regular cells (cellular space), each one embedding an identical finite automaton $(f a)$, whose input is given by the states of neighbouring cells; $f a$ have an identical transition function, which is simultaneously applied to each cell. At time $t=0, f a$ are in arbitrary states and the $C A$ evolves changing the state of all $f a$ simultaneously at discrete times, according to the transition function of the $f a[8]$.

An empirical method [8], applied successfully to macroscopic phenomena, as lava flows [2], [5] and debris/mud flows [7], [1], [10], was followed and adapted to particular features of pyroclastic flows. The following assumptions are adopted:

- Each characteristic, that is considered relevant to the evolution of the system and relative to the space portion corresponding to the cell, is individuated as a substate. The set of states is the Cartesian product of the sets of substates.

- As the state of the cell can be decomposed in substates, the transition function may be split in many local interactions: the "elementary" processes. Their composition generates the complexity of the phenomenon. The elementary processes are applied sequentially according a defined order.

- The pyroclastic matter content of each cell is ideally divided in as many parts as the number of the neighbourhood cells; each part is compared with the adjacent part of the neighbouring cell. A pyroclastic flow between the two parts is determined in order to minimise the height differences; height is comprehensive of altitude, deposit thickness and pyroclastic matter elevation.

The phenomenon evolution is considered since the beginning of the column collapse phase (comprehensive of an initial feeding) up to the exhaustion of the deposition phase; some simplifications concerning the phenomenon nature are assumed:

- The pyroclastic matter (gas and solid particles) is considered homogeneous in its composition; its behaviour is not considered dependent on the temperature.

- Pyroclastic matter attributes (inside the cell) are specified by elevation, coordinates and velocity of its barycentre.

- Complex behaviours as turbulence are reduced to simple displacements of pyroclastic matter between couples of cells; of course the energy loss is modelled in such a way that high energy in pyroclastic flows, corresponding to turbolence conditions, involves larger energy losses according to reasonable empirical laws. 


\subsection{PYR Main Specifications}

PYR is a deterministic two-dimensional $C A$ model for pyroclastic flows with square cells; it is defined by the septuple PYR $=<\boldsymbol{R}, \boldsymbol{G}, \boldsymbol{X}, \boldsymbol{S}, \boldsymbol{P}, \sigma, \boldsymbol{\gamma}$ where:

$-R=\left\{(x, y) \mid x, y \in N, 0 \leq x \leq l_{x}, 0 \leq y \leq l_{y}\right\}$ is the set of points with integer coordinates in the finite region, where the phenomenon evolves. $N$ is the set of natural numbers.

- $G$ is the set of cells, corresponding to the area, where the volcanic column begins to collapse; such cells generate the pyroclastic phenomenon.

- The set $X=\{(0,0),(0,1),(0,-1),(1,0),(-1,0)\}$ identifies the geometrical pattern of the cells, which influence the cell state change. The cell $(0,0)$ is called the central cell.

- $S=S_{A} \times S_{X} \times S_{Y} \times S_{Z} \times S_{E} \times S_{V} \times S_{T H} \times S_{O E}{ }^{4} \times S_{O V}{ }^{4} \times S_{I E}{ }^{4} \times S_{I V}{ }^{4}$ is the set of states; the meaning of the substates is specified in table 1 .

- $P=\left\{p_{s}, p_{v}, p_{e r}, p_{p d r}, p_{S P}, p_{G}\right\}$ is the finite set of PYR global (invariant in time and space) parameters, which effect the transition function; their meaning is specified in table 2 .

- $\sigma . S^{5} \rightarrow S$ is the deterministic state transition. It is specified by four elementary processes in application order: degassing and particles deposition, internal shift of the pyroclastic column, outflows, composition of outflows and inflows inside the cell.

- $\gamma: N \rightarrow S_{E}$ specifies the feeding of pyroclastic material for cells of $G$, where the volcanic column begins to collapse. $N$ is referred to the steps of $C A$.

Table 1. List of substates and their meaning. The values related to inflows are the same of the corresponding outflows in the neighbourhood cells.

\begin{tabular}{|c|c|}
\hline Substate & Meaning \\
\hline$S_{A}$ & altitude of the cell \\
\hline$S_{X}, S_{r}, S_{Z}$ & $\begin{array}{l}\text { co-ordinates } x, y, z \text { of the barycentre of the pyro- } \\
\text { clastic column in the cell }\end{array}$ \\
\hline$S_{E}$ & elevation of the pyroclastic column in the cell \\
\hline$S_{V}$ & velocity of the pyroclastic column in the cell \\
\hline$S_{T H}$ & thickness of solid particles deposits in the cell \\
\hline$S_{R T}$ & $\begin{array}{l}\text { residual time of the } C A \text { step during which the } \\
\text { outflow may move }\end{array}$ \\
\hline$S_{O X}, S_{O Y}, S_{O Z}$ & $\begin{array}{l}\text { co-ordinates } x, y, z \text { of the barycentre outflow from } \\
\text { the central cell toward a neighbour cell }\end{array}$ \\
\hline$S_{I X}, S_{I Y}, S_{I Z}$ & $\begin{array}{l}\text { co-ordinates } x, y, z \text { of the barycentre the inflow, } \\
\text { trivially derived by } S_{O X}, S_{O Y}, S_{O Z}\end{array}$ \\
\hline$S_{O E}, S_{I E}$ & $\begin{array}{l}\text { outflow from the central cell toward a neighbour } \\
\text { cell and inflow, trivially derived by } S_{O E}\end{array}$ \\
\hline$S_{O V}, S_{I V}$ & $\begin{array}{l}\text { outflow velocity and inflow velocity, trivially } \\
\text { derived by } S_{O V}\end{array}$ \\
\hline
\end{tabular}


Note that PYR is two-dimensional, but the third dimension is effectively introduced because the morphology is represented by values of $S_{A}$, the deposit thickness is specified by the values of $S_{T H}$, the elevation of the column of solid particles is specified by values of $S_{E}, S_{Z}$ values refer to the co-ordinate $Z$ of its barycentre.

The co-ordinates $X$ and $Y$ are related to the center of the cell; the co-ordinate $Z$ is related to the sea level. Note that the execution of each elementary process updates the values of the involved substates.

Initial conditions are given by specifying the values of $S_{A}$ according the morphology; only the cells, corresponding to the space portion where the volcanic column begins to collapse, have values of $S_{E}$ different from zero; the pyroclastic content is considered to be distributed homogeneously starting from the surface: the pyroclastic column inside the cell rests on the soil and the barycentre co-ordinates $X$ and $Y$ are null.

The values of substates, concerning flows, are initially null.

Table 2. List of global parameters and their meaning.

\begin{tabular}{cl}
\hline Parameter & \multicolumn{1}{c}{ Meaning } \\
\hline$p_{s}$ & side of the cell \\
$p_{\text {step }}$ & time corresponding to a $C A$ step \\
$p_{S P}, p_{G}$ & $\begin{array}{l}\text { solid particles and gas content of pyroclastic col- } \\
\text { umn in the cell (in percent: } p_{S P}+p_{G}=100 \text { ) }\end{array}$ \\
& $\begin{array}{l}\text { the degassing - particles deposition relaxation rate } \\
p_{\text {elr }}\end{array}$ \\
$p_{\alpha}$ & (elevation loss rate) \\
& is a parameter ruling the friction effect
\end{tabular}

\section{PYR Transition Function}

The "elementary" processes are specified in terms of equations or expressed as Pascallike procedures, where names of parameters and substates are derived by the lower indexes specified in the section 2.1: the parameter $p_{\text {name }}$ is indicated as name; $s_{\text {name }}$, $\Delta s_{\text {name }}$ and $n \_s_{\text {name }}$ indicate respectively the value of substate $S_{\text {name }}$, its variation and the new value; when the specification of the index $i$ of a neighbourhood cell is necessary, the notation $s_{\text {name }}[i]$ is adopted; a couple of index $i, j$ needs for the flows: $s_{\text {Fname }}[i, j]$ means the value of the flow substate name from the cell $i$ toward the cell $j$ in the neighbourhood ( $i=0$ for the outflows, $j=0$ for the inflows).

\subsection{Degassing and Particles Deposition}

Pyroclastic flow degassing and particles deposition are obtained by a simple empirical law: at each step a segment (it is $p_{e l r}$ during a second) of the pyroclastic column is lost the corresponding part of gas leaves the column and the corresponding part of particles is deposited.

The following Pascal-like procedure illustrates this elementary process: 


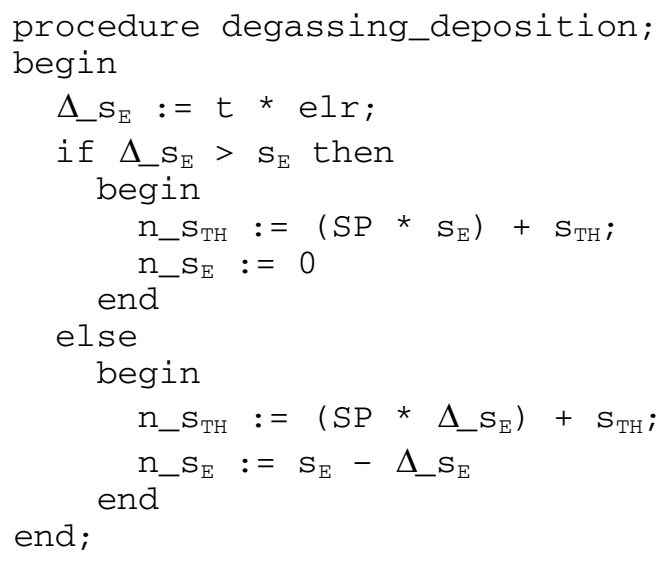

\subsection{Internal Shift of the Pyroclastic Column}

The pyroclastic column inside the cell could not lay on the surface (soil or pyroclastic deposit); in this case the barycentre must reach the "objective point" (i.e., the column must reach the surface and the co-ordinates $x$ and $y$ of the barycentre must be null); this shift (distance $d$ ) of the barycentre from the initial point to the objective point is managed by the following empirical equations (1), (2), (3), (4), where the motion of the pyroclastic column is depending on the gravity force, that is opposed by friction forces. An asymptotic velocity limit is considered because the effect of the friction forces increase as the velocity increases. The following four equations, similar to the Stokes equations, are adopted; they are deduced in sequence: $F$ is the force, $m$ is the mass of the pyroclastic matter inside the cell, $t$ is the time, $v$ is its velocity, $v_{0}$ is the initial velocity, $\theta$ is the angle of the path slope to the objective point, $\alpha$ is the friction parameter. The equation (4) computes the length $\Delta$ covered in a time $\Delta t$.

$$
\begin{gathered}
F=m g \operatorname{sen} \theta-\alpha m v . \\
d v / d t=g \operatorname{sen} \theta-\alpha v . \\
v=\left(v_{0}-g \operatorname{sen} \theta / \alpha\right) e^{-\alpha t}+(g \operatorname{sen} \theta / \alpha) . \\
\Delta=\left(v_{0}-g \operatorname{sen} \theta / \alpha\right)\left(1-e^{-\alpha \Delta t}\right) / \alpha+(g \operatorname{sen} \theta / \alpha) \Delta t .
\end{gathered}
$$

The $C A$ step could be insufficient in order to cover the distance ( $d>\Delta$ for $\Delta t=s t e p$ ). In this case the new co-ordinates of the barycentre are determined. Conversely, if the objective point is reached, then outflows may be permitted for the residual time of the CA step, if the appropriate conditions occur (next subsection). 


\subsection{Outflows}

The pyroclastic column is divided in four parts in correspondence of the neighbouring cells (barycentres with same Z, different $\mathrm{X}$ and $\mathrm{Y}$ ). Each part (1/4 of the mass) is sensible only to the corresponding part of the neighbouring cell. The computation of outflows is based on the difference of height (in this case, height is the sum of altitude, pyroclastic deposit and pyroclastic column); there are two constrains: the maximum outflow is $1 / 4$ of the mass (fig.1a), the top of the outflow in the arrival cell don't have to be higher than the bottom of the outflow in the departure cell (fig.1b).

The barycentre follows the path with velocity computed according the formulae of the previous subsection. Outflow is composed as inflow in the neighbouring cell with other inflows and the residual part of pyroclastic column (next subsection).
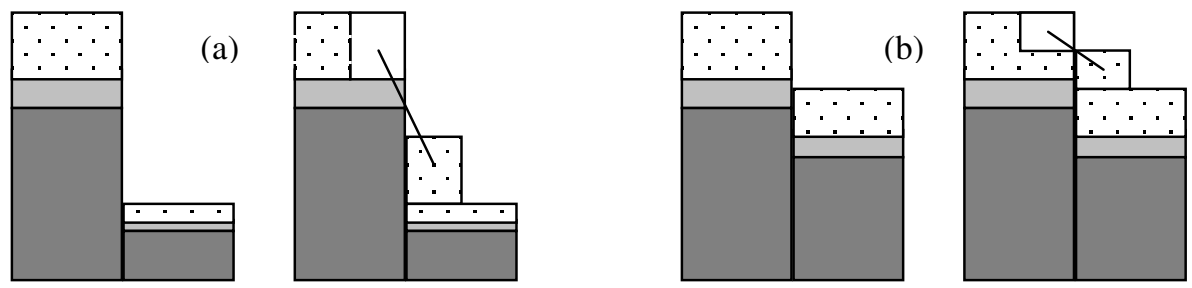

Fig. 1. A path of outflow between two adjacent cells (in vertical section) is shown in two cases: the altitude is in darker grey, the deposit is in lighter grey, the pyroclastic column elevation is in dotted filling. Initial conditions are at the left, the path is drawn at the right for both figures

\subsection{Composition of Outflows and Inflows inside the Cell}

This last "elementary" process calculates the final values of the substates elevation, considering balance of outflows and inflows; new co-ordinates and velocity of the barycentre are obtained by a weighted average.

$$
\begin{gathered}
n_{-} s_{E}[0]=s_{E}[0]+\sum_{i=1}^{4}\left(s_{F E}[i, 0]-s_{F E}[0, i]\right) \\
n_{-} s_{X}[0]=\left(s_{E}[0] s_{X}[0]+\sum_{i=1}^{4}\left(s_{F E}[i, 0] s_{F X}[i, 0]-s_{F E}[0, i] s_{F X}[0, i]\right)\right) / n_{-} s_{E}[0]
\end{gathered}
$$

$n \_s_{Y}[0]$ and $n \_s_{Z}[0]$ are obtained just substituting the indexes " $\mathrm{X}$ " in the equation (6) respectively with the indexes " $\mathrm{Y}$ " and " $\mathrm{Z}$ ".

$$
n_{-} s_{V}[0]=\left(s_{E}[0] s_{V}[0]+\sum_{i=1}^{4}\left(s_{F E}[i, 0] s_{F V}[i, 0]-s_{F E}[0, i] s_{F V}[0, i]\right)\right) / n_{-} s_{E}[0]
$$




\section{The Pinatubo 1991 Eruption}

Mount Pinatubo is situated on the island of Luzon, about $80 \mathrm{~km}$ northeast of Manila, the capital of the Philippines. The volcano started its activity about 1.1 million years ago and is characterised by a set of lava domes surrounded by thick deposits of pyroclastic materials. The eruptive activity is scanned by eruptions separated by diverse centuries of quiescence; eruptions are mainly explosive, of large intensity, characterised by emissions of diverse $\mathrm{km}^{3}$ of ash and pumices usually followed by the formation of lava domes. The 1991 eruption is one of the major eruptions of this century. Mt. Pinatubo has returned to activity after a rest of more than 600 years [14].

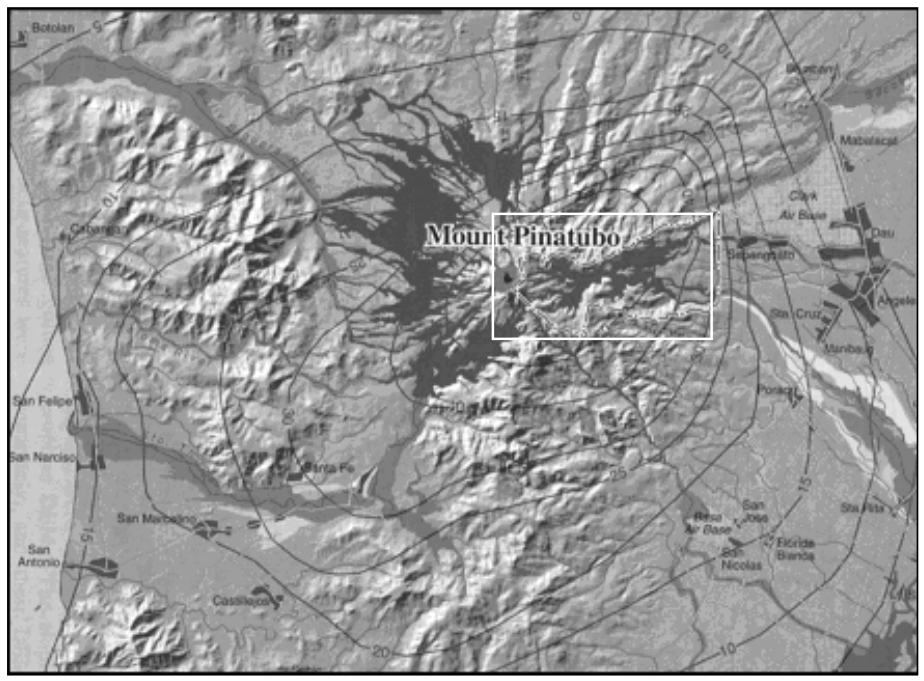

Fig. 2. The effects of the 1991 eruption of the Pinatubo. The areas in darker grey around the Mt Pinatubo represent the deposits. The white frame encloses the Sacobia river valley

The flows that were generated in the 1991 eruption and their ash clouds travelled for about $15 \mathrm{~km}$ from the main vent, covering an area of ca $400 \mathrm{Km}^{2}$ (fig.2). The major part of the deposits consists of pumiceous pyroclastic flows with minor lithic-rich facies. Their asymmetric distribution is strongly controlled by the pre-eruptive morphology of the area. In fact, the western morphology of the volcano is relatively flat with respect to the eastern part, which is more mountainous. The steep morphology of the southern and southeastern part could have deviated the flow towards southwest in the Marella valley. In the same way, even the flows towards north and northeast could have been deviated toward northwest in the O'Donell and Bucao valleys due to the steep morphology which is present in the north-east area. The only flow that has deposited material in the eastern part of the volcano is situated in the Sacobia and Pasing Rivers valleys [6], [14].

Our simulations refer exclusively to the Sacobia area (fig.2, inside the white frame) because of the good pre and post eruption available geo-morphological data. The pre- 
eruptive and post-eruptive geomorphologic maps have been obtained by computer generated DEMs by A. Daag and J. C. van Westen [6]. The post-eruptive situation is represented by fig.3.a, where the area occupied by the pyroclastic flow is shown.

\section{Simulation Results}

The PYR model is an empirical instrument based on the paradigm of the Cellular Automata, which are highly non linear systems. Therefore global parameters plays a crucial role: very different simulations are generated changing slightly the parameters value. Some parameter value is imposed by choices $\left(p_{s}, p_{\text {step }}\right)$ or by features of the phenomemon $\left(p_{S p}, p_{G}\right)$, some parameters are empirically deduced by the results of the simulations in a range of reasonable values $\left(p_{e l r}, p_{\alpha}\right)$.

Several simulations were carried out to devise the optimal empirical parameters of the PYR model. The values of parameters, that are used in the best simulation (fig.3b), are reported in the table 3 .

Initial conditions of the phenomenon represent another crucial point: their evaluation is approximated, it can differ for different observers. The initial pyroclastic column before the collapse was estimated $\mathrm{Km}$. $5 \mathrm{high}$; the initial area, underlying the pyroclastic column, occupies hundred cells. The duration of the main event is estimated approximately one hour long.

The dimensions of the matrix are $264 \times 385$, i.e., the number of cells of the CA along the $\mathrm{x}$ and $\mathrm{y}$ directions that need to cover the extension of the studied area.

The application results of this CA first model to a real event, namely the $1991 \mathrm{Pi}-$ natubo eruption, are very encouraging. If the real event (fig.3a) is compared with the simulated event (fig.3b), a good correspondence for the areas covered by the pyroclastic flow can be evidenced in the precision limits of the cell side. The main flow paths are individuated correctly, the deposits of solid particles are realistic in the control effected on the final configuration of the simulation.

PYR was implemented in Delphi; the program permits step by step to read the substates values for each cell; the morphology is represented by level curves, the cells corresponding to a surface covered by the pyroclastic flow became black (fig. $3 b$ ).

Table 3. Values of the global parameters in the Mt Pinatubo simulation.

\begin{tabular}{cl}
\hline Parameters & \multicolumn{1}{c}{ Values } \\
\hline$p_{s}$ & side of the cell: $\mathrm{m} .50$ \\
$p_{\text {step }}$ & time corresponding to a $C A$ step: s. 0.05 \\
$p_{S P}, p_{G}$ & solid particles $30 \%$, gas content $70 \%$ \\
$p_{\text {elr }}$ & elevation loss rate: $\mathrm{m} 0,3$ \\
$p_{\alpha}$ & friction parameter 0,098 \\
\hline
\end{tabular}




\section{Comment and Conclusion}

Pyroclastic flow numerical models, used in simulation of real events, are not many.

Wadge et al. [13] simulated the pyroclastic flows generated by the 1996 eruption of the Soufrire Hills volcano, Monserrat. Their method uses simplified equations; successful simulation of the flow avalanche component is the basis for surge simulations.

Itoh et al. [11] adopt physical and empirical assumptions, that define differential equations, solved with finite differences method (similar to a $C A$ approach). Interesting results were obtained for the Merapi volcano pyroclastic flows.

Other models are based strictly on physical equations and use sophisticated numerical methods, but they haven't be utilised for happened cases , e.g. Dobran et al. [9].

The PYR model didn't give inferior results than other simulations of real cases; but it needs less approximations. The assumption, that the pyroclastic content in a cell is sensible only to the next cell, is weak; it works for smallest step values. The minimisation algorithm [8] will be opportunely introduced in the new model.
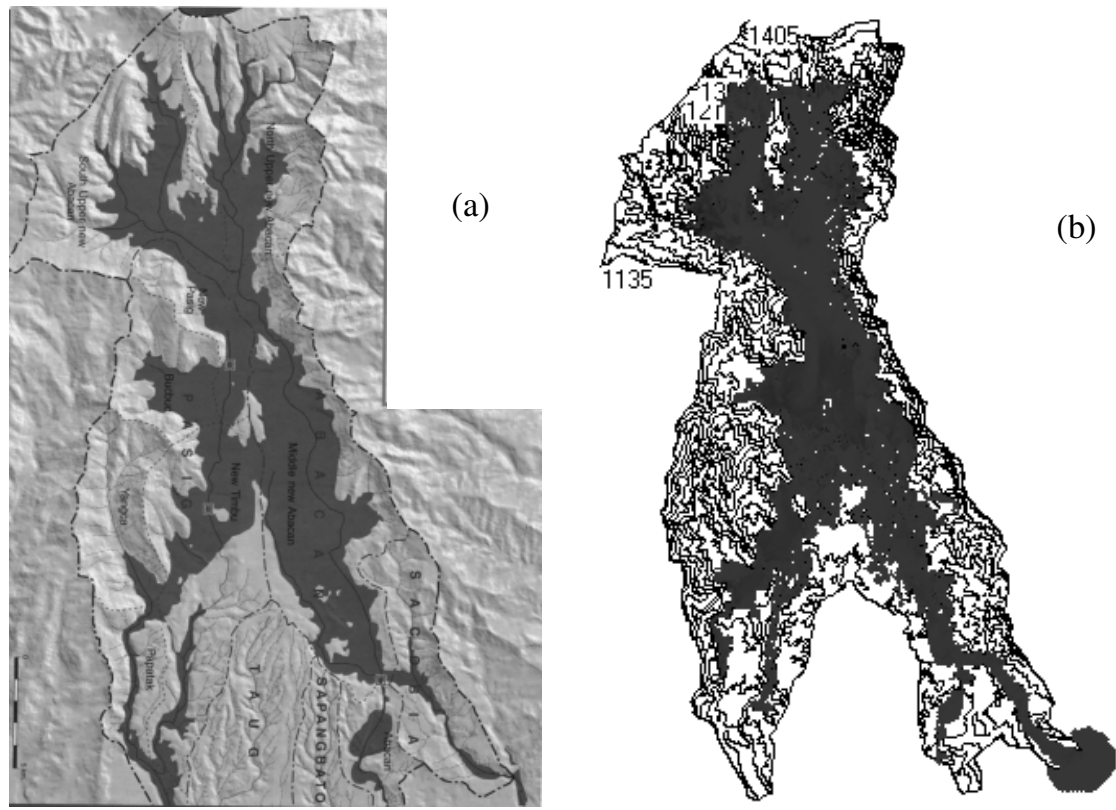

Fig. 3. The pyroclastic deposits in Sacobia river valley after the 1991 eruption of the Pinatubo are represented in darker grey in (a) for the real event and in black on surface curves in (b) for the simulated event

This $C A$ approach permits usually to start from simple models, that need few elementary processes and substates; then the model, so far developed, can be straightforwardly enriched, complicating the transition function and/or adding new elementary processes and substates to account situations of increasing complexity. 
When the model will be tuned for several different cases of pyroclastic flows, then applications would be reliable in order to determine hazard areas.

Acknowledgements. The authors thank Prof. C.J. van Westen and Dr. A. Daag for supplying pre-eruptive and post-eruptive morphology together with studies on the phenomenon features and evolution.

\section{References}

1. Avolio, M.V., Di Gregorio, S., Mantovani, F., Pasuto, A., Rongo, R., Silvano, S., Spataro, W.: Simulation of the 1992 Tessina landslide by a cellular automata model and future hazard scenarios. JAG 2, 1 (2000) 41-50

2. Barca, D., Crisci, G.M., Di Gregorio, S., Nicoletta, F.: Cellular Automata for simulating lava flows: a method and examples of the Etnean eruptions. Transport Theory and Statistical Physics, 23, 1-3, (1994) 195-232

3. Bryant, E.A.: Natural Hazards, Cambridge University Press, New York, (1991)

4. Chester, D.: Volcanoes and Society, Edward Arnold (ed.), London (1993)

5. Crisci, G.M, Di Gregorio, S., Nicoletta, F., Rongo, R., Spataro, W.: Analysing lava risk for the Etnean area by Cellular Automata methods of simulation. Natural Hazards, 20 (1999) 215-229

6. Daag, A., van Westen, C.J.: Cartographic modelling of erosion in pyroclastic flow deposits of Mount Pinatubo, Philippines. ITC Journal, 2, (1996) 110-124

7. Di Gregorio S., Rongo R., Siciliano C., Sorriso-Valvo M., Spataro W.: Mount Ontake landslide simulation by the cellular automata model SCIDDICA-3. Physics and Chemistry of the Earth, A, 24,2 (1999) 97-100

8. Di Gregorio S., Serra R.: An empirical method for modelling and simulating some complex macroscopic phenomena by cellular automata. Future Generation Computer Systems, 16 (1999) 259-271

9. Dobran F., Neri A., Macedonio G.: Numerical simulation of collapsing volcanic columns. Journal of Geophysical Research, 98, B3 (1993) 4231-4259

10. Iovine, G., Di Gregorio, S., Lupiano. V.: Debris-flow susceptibility assessment through cellular automata modeling: an example from 15-16 December 1999 disaster at Cervinara and San Martino Valle Caudina (Campania, southern Italy). Natural Hazards and Earth System Sciences 3 (2003) 1-12

11. Itoh, H., Takahama, J, Takahashi, M., Miyamoto, K.,: Hazard estimation of the possible pyroclastic flow disasters using numerical simulation related to the 1994 activity at Merapi Volcano. Journal of volcanology and geothermal research (2000) 503-516

12. Succi, S.: The Lattice Boltzmann Equation for Fluid Dynamics and Beyond, Oxford University Press, Oxford (2001)

13. Wadge G., Jackson, P., Bower SM., Woods A.W., Calder E.: Computer simulations of pyroclastic flows from dome collapse. Geophysical Research Letters, 25, 19 (1998) 36773688

14. Wolfe, E.W.: The 1991 eruptions of Mount Pinatubo, Philippines. Earthquakes and Volcanoes, 23, 1 (1992) 5-37 